\title{
Digital Comics: An Introduction
}

\author{
DANIEL MERLIN GOODBREY, University of Hertfordshire \\ JAYMS CLIFFORD NICHOLS, University of Hertfordshire
}

Welcome to a special issue of Networking Knowledge focused on the study of digital comics. The study of comics is a rapidly expanding and evolving field of academic and cultural discourse. This edition of the journal aims to offer a portal into the growing area of the field that focuses specifically on the relationship between comics and digital media.

Digital technology is changing the ways that we consume media in our day to day lives. As new and different technologies become integral to our culture, our consumptive habits of media change around these technologies. This is true of television, film, magazines and, of course, comics. Comics are a form of sequential art that has always evolved alongside the technology of the time. With the widespread adoption of the printed page comics found a home as short, black and white strips in newspapers. As printing processes became more advanced and visual quality increased, comics developed into the colourful, serially printed books that we see today.

In more recent times a similar evolution can be seen in digital comics. The widespread adoption of computers and the culture-shattering impact of the Internet lead to comics finding a new home within a digital environment. Now, as the number of portable display platforms and the quality of digital display continues to increase, so too do the number of comics available digitally. It is against this background that we present a series of papers examining several key aspects of the evolution of comics as a digital medium.

We start, suitably enough, with a paper that aims to help define the comics medium in the digital environment; Lukas R. A. Wilde's 'Distinguishing Mediality: The problem of identifying forms and features of digital comics'. Wilde's paper examines the extent to which digital comics constitute a different medium to print comics. He discusses the lack of a defining technology of the medium and the perceived differences and similarities between digital and print comics. The paper aims to show how we can observe digital comics as new objects of inquiry and offers distinctions that allow us to learn about the changing cultural implications for the comic form.

We then get stuck into the World Wide Web with three papers that discuss the world of webcomics, starting with Paddy Johnston's paper, 'Bad Machinery and the economics of free comics: A webcomic case study'. His article presents a case study of successful webcomic cartoonist, John Allison. It examines Alison's work and how a creator can make free webcomics an economically viable form of labour. Johnston also presents a critical framework through which we can understand webcomics as labour even when produced and distributed for free.

Following this we have a paper from Gabriel E. Romaguera entitled 'Waiting for the next part: How the temporal dimensions of digital serialisation have changed author-reader dynamics'. The paper discusses the release schedules of online webcomics and how these 
impact the relationship between the creator and the reader. It offers a case study of the web cartoonists Rich Burlew and Tarol Hunt, comparing and contrasting their publication schedules and the audience reaction to the different regularities of these serialisations.

The third paper in our run on webcomics is by Roger Dale Jones. It focuses not on the study of professional web cartoonists but instead on the fan creators of the World of Warcraft videogame community. His paper, 'Approaching the cognitive and social functions of World of Warcraft fan-comics', presents a critical framework that combines game discourse, game narrative and sense-making in comics. It discusses how fans of World of Warcraft use digital comics to explore the themes and social conventions of the game. The framework is used in an analysis of three different World of Warcraft fan-comics that present different levels of game discourse and sense making processes.

We then move away from webcomics to two papers that look at drastically different digital comic forms and ways of delivering digital comics to an audience. Damian Duffy's paper, 'Hyper/comics/con/text: Institutional contexts and interface design in online educational hypercomics', looks at hypercomics; a form of digital comic with reader interaction and choice making at its core. Duffy examines two educational hypercomics in depth; Factoring with Mr. Yang and Mosley the Alien and The Secret in the Cellar. He then provides a comparison of their purpose, design and institutional origins.

Lastly we move to something completely different with Mathias P. Bremgatner's paper, 'Performing 'readings': The Interplay of theatre and digital comics in TeZukA'. This paper discusses the projected digital comics presented as part of a theatrical performance celebrating the life and work of Japanese cartoonist Osamu Tezuka. In his paper, Bremgatner argues that the performance demonstrates different ways of delivering, reading and interacting with digital comics. He discusses the cultural significance of comics in theatrical performance and examines how tropes of digital reading enter the performance through the artists on stage.

This broad range of topics is just a small part of an important and growing field of studies; a field that is sure to grow larger as comic readers spend increasing amounts of time online, consuming comics across a multitude of digital displays. These papers offer us a glimpse into a range of forms of digital comics, from fan-made webcomics to projected performance pieces. With the current wealth of academic study into comics and the growing importance of digital technology for media consumption, it is for certain an exciting time to be involved in digital comics theory.

Daniel Merlin Goodbrey is a lecturer in Narrative \& Interaction Design at The University of Hertfordshire. A prolific and innovative comic creator, Goodbrey has gained international recognition as a leading expert in the field of experimental digital comics. His hypercomic work received the International Clickburg Webcomic Award in Holland in 2006 while his work in print was awarded with the Isotope Award for Excellence In Comics in San Francisco in 2005. His smartphone app, A Duck Has An Adventure was shortlisted in the 2012 New Media Writing Prize. An archive of his work can be found at http://emerl.com/consulting

Email: d.m.1.goodbrey@herts.ac.uk 
Jayms Clifford Nichols: Jack of all trades, master of one. Jayms is an active digital practitioner with knowledge of most digital creative processes and packages and skills ranging from digital drawing to photography and video-making. He has a masters in Hyperfiction (interactive media with a story telling focus) and is also an academic studying the field of digital comics and screen reading in which he is working towards a PhD. He teaches Mass Communications and Interactive Media and Screen Cultures at the University of Hertfordshire focusing on digital design processes, animation and web design. He also records and edits videos in his spare time around his writing of papers about digital comics.

Email: jayms.wisdom@gmail.com 